\title{
Determining Containership Loading Problem on the Basis of an Adopted Number of Handling Cranes
}

\author{
Nguyen Thanh Thuy*, Etsuko Nishimura** and Akio Imai**
}

\begin{abstract}
Faster turnaround time of vessels is one of paramount factors in a container terminal for assuring competitive advantage in the shipping industry, which can be achieved by efficient handling process of vessels, especially the associated loading plan in the loading sequence. This paper deals with the ship loading problem regarding to the number of cranes to be used in a loading process while keeping reasonable ship stability. In order to preserve the ship stability, some heavier containers may be stowed at the bottom of ship holds. When those containers are stacked below others on a yard container block which are withdrawn later, it may required a number of rehandles when they are retrieved from the blocks. The efficient of loading process is evaluated by the minimum number of container rehandles required. To solve this problem, a mix integer programming is formulated. The genetic algorithm, which is widely applied for a plenty of practical mathematical programming, is employed as a heuristic for the nearly optimized solutions and a wide variety of numerical experiments was made where solutions by this problem are useful and applicable in practice.
\end{abstract}

Keywords: Containership handling; Container rehandles; Genetic Algorithm; Logistics

\section{Introduction}

Worldwide container trade has maintained constant growth since 1980's with average growth rate of $9.5 \%$ per year during last decade, $8 \%$ per year from 2000 to 2003 and this rate still increasing in coming years. Therefore, in order to respond this increase in containerization, the efficiency of container transportation system should be raised in which the container ship scheduling is regarded as a complex dynamic application. Fast turnaround of ships becomes a dominant factor for assuring competitive advantage of the liner shipping companies as well as container ports, which can be achieved by efficient handling process of vessels, especially the associated loading plan in the loading sequence.

The efficiency of loading process depends on the number of redundantly repositioning activities when loading containers from yard onto the ship. In a loading sequence, if the target container is stacked below others in a container block on a yard which are to be pickup later, because of the ship's balance and other reasons, then the loading task requires the so-called "rehandle" in order to remove and reposition the others. Such a rehandle problem may not be important in big container terminals where very large containerships call, since a large number of containers are handled at the same time and there is much flexibility for a loading sequence. In addition, the rehandle problem will not be present in case the terminal uses the chassis system for terminal handling. However, for a relatively small size container terminal with medium size calling vessels, in which transfer crane system or straddle carrier system are used, the rehandle problem is significant.

A way to avoid rehandles during a loading operation would be container shuffling in advance of loading. Nevertheless, this necessitates an additional workload for the handling equipment, which is more

\footnotetext{
* Student Member

Graduate School of Science and Technology, Kobe University, (5-1-1 Fukae, Higashinada, Kobe 658-0022) 039d956n@stu.kobe-u.ac.jp 
intense than the total workload of rehandling during the loading operation. This could be done only when the handling equipment is idle. In addition, smooth shuffling requires a buffer stack area where containers to be loaded are moved orderly from the storage area but such a buffer area is hardly practical or realistic for container terminals in land scarce countries.

In order to reduce the containership handling time at container terminal, this paper addresses the ship loading problem (SHCP) in comparatively low volume handling terminal by maximizing the ship stability and minimizing the number of rehandled containers, as well as analyze the effect of number of handling cranes on the loading sequence.

\section{Literature review}

One of the earliest works on the ship handling problem was conducted by Imai and Miki (1989) who considered the minimization of loading related rehandle in conjunction with maximization of megacenter height (GM) when loading containers onto one of ship holds. Next of their study (Imai et al., 2002) considered a problem only for finding non-inferior solutions with acceptable GM, while Imai et al. (2006) concentrated on the relationship between the ship stability (including GM, list and trim) and the loading-related rehandles.

Also conducting a ship load planning problem with the transfer crane system, Martin et al. (1988) developed a heuristic algorithm based on the rules of thumb prevalent in a terminal that was the minimization of the transfer crane movement time and the minimization of the unloading-related rehandles. In contrast, Avriel et al. (1998) concentrated on a stowage problem that only minimized the unloading related rehandles for loading onto a single ship hold without any consideration for ship's stability. The same problem was solved by Dubrovsky et al. (2002), implemented a genetic algorithm (GA)-based heuristic. Haghani and Kaisar (2001) developed GA for ship stowage planning by cost. Wilson and Roach (2000) and Wilson et al. (2001) built up a realistic model in which the approach was processed into two phases: strategy and tactical process. Zhang et al. (2002) addressed the crane deployment problem. However, no details of the stability were described.

More recently works were conducted by
Ambrosino and Sciomachen (2004), and Sciomachen and Tafani (2006), in which some ship holds were assigned to containers of the same destination in order to avoid unproductive work in unloading and loading sequence. However, loading related rehandle was not mentioned there.

\section{Model development}

\subsection{Model assumptions}

In order to explain the problem, some simplifications and assumptions are made as follows:

(a) The containership has cellular structure or LOLO

(b) Some containers have already been stowed on board of the ship before loading containers in question.

(c) Transfer crane system (Rubber Tired Gantry Crane- RTG or Rail Mounted Gantry Crane- RMG) is considered throughout this study. Each container block of a terminal has at least one RTG or RMG to serve. It is assumed that one RTG (or RMG) at a block serves containers to be loaded by a quay crane (QC) during loading sequence, as shown in Fig. 1.

(d) GM is used as the ship stability factor in this study. In practice, other two stability factors are taken into consideration: list and trim. However, stability issues caused by those two factors can be dealt by using ballast; therefore they are not considered in this study.

(e) Each container has the same center of gravity, i.e., the weight is imposed at the center of container along three axes. Therefore, containers have their overall center of gravity at their middle location.

(f) Containers are loaded into ship holds by destination.

\subsection{SHCP Model}

\subsubsection{Container rehandles evaluation}

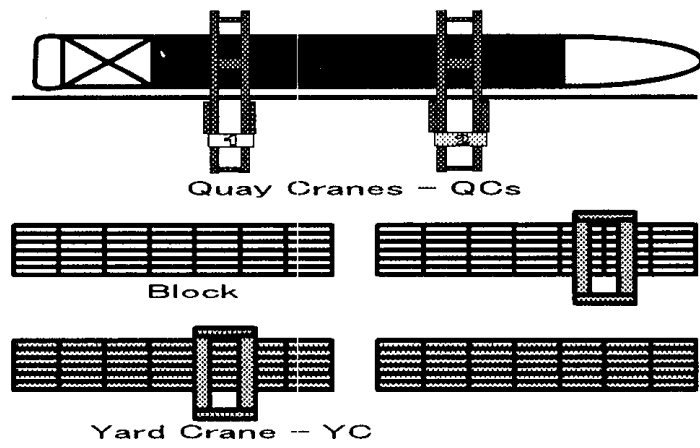

Fig. 1 Example of container handling sequence 
Referring to Imai and Miki (1989), Imai et al. (2002) and Imai et al. (2006), the estimated number of rehandles is utilized in order to take the rehandle objective into account in the formulation. The rehandle is estimated based on the expected number of rehandles when retrieving each container in a block as the first one to be taken. Fig. 2 illustrates a loading process with loading rehandle, where there are two sections (or yard bays) of a container block on the yard shown in the left hand-side of the figure and a ship's cross sectional view (or ship bay) are shown in the right. In this figure, the numbers on yard bays indicate positions of containers in the bays, while the numbers in the ship bay designate the order of a loading sequence (from dock side to the sea side). As an example, the container in position \#3 of first yard bay is loaded into the ship bay as the first container in loading sequence. Therefore, the container in yard position \#4 should be moved in order to reach the container in yard position \#3, which causes one rehandle as being calculated.

With the assumption that container locations in a bay of the yard are given the serial number, the following notations are used:

$R L_{i j k}$ : the expected number of rehandles to withdraw a container of location $i$ of yard bays as the $f^{\text {th }}$ container (which is placed in its corresponding position in the ship bay) by crane $k$

$B$ : $\quad$ the number of containers in the bay

$N$ : $\quad$ set of loaded containers

$M$ : $\quad$ set of number of assigned QCs (YCs)

$R L_{i j}$ : number of containers to be rehandled when a container at location $i$ of yard bays is picked up as the first container in the loading sequence

The variable is defined as follows:

$x_{i j k}: \quad=1$ if the container at position $i$ of yard bays is loaded as the $j^{\text {th }}$ container by crane $k$ in the loading sequence, $=0$ otherwise

In Imai et al. (2002), the number of loading rehandles is estimated based on the expected number

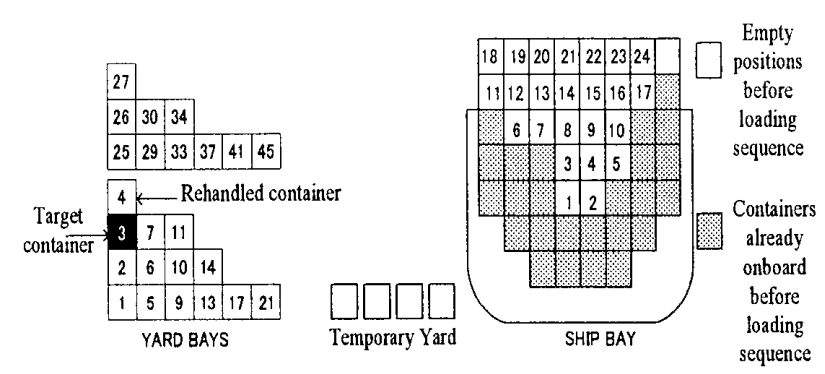

Fig.2 Loading sequence with rehandles

of rehandles when retrieving each container in the block as the first one to be taken. When withdrawing the target container as shown in Fig.2, the expected number of the hatch containers to be rehandled is obtained. A set of $j-1$ containers is retrieved with the probability of $\frac{j-1}{B-1}$ before another container is loaded as the $j^{t h}$ one. Therefore, the probability that at least one of the $j-1$ containers is not retrieved is:

$$
1-\frac{j-1}{B-1}
$$

The number of containers remaining among the hatched ones is defined as:

$$
R L_{i j k}=\left(1-\frac{j-1}{B-1}\right) R L_{i j}
$$

Based on this concept, the model of container loading sequence considering to number of cranes employed in handling sequence is developed, which make the ship stowage plans obtained become more practical than the previous model implemented by Imai et al. (2002). The model is presented as follows: [PR]

Minimize $\sum_{i=1}^{N} \sum_{j=1}^{N} \sum_{k=1}^{M} R L_{i j k} x_{i j k}$

Subject to

$$
\begin{array}{ll}
\sum_{i=1}^{N} \sum_{j=1}^{N} x_{i j k}=1 & \text { for } k=1,2, \ldots, M \\
\sum_{i=1}^{N} \sum_{k=1}^{M} x_{i j k}=1 & \text { for } \quad j=1,2, \ldots ., N \\
\sum_{j=1}^{N} \sum_{k=1}^{M} x_{i j k}=1 & \text { for } i=1,2, \ldots ., N
\end{array}
$$

Table 1 Example of loading expected rehandles obtained from Fig.2 with number of QCs (YCs) $=1$

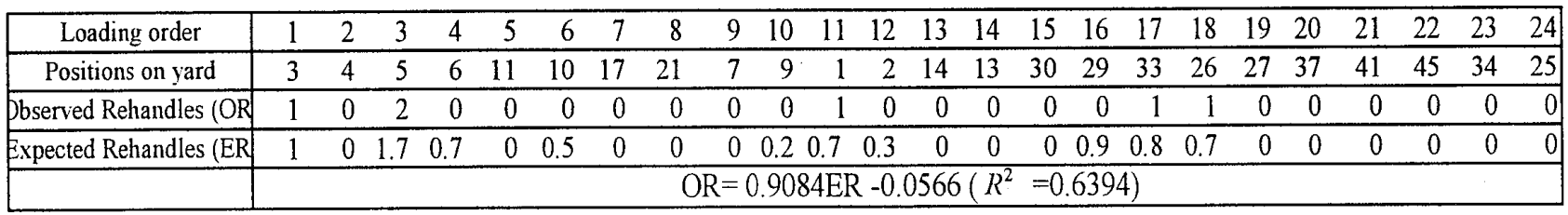




$$
x_{i j k} \in\{0,1\}
$$

Objective (3) is the minimization of the total number of loading related rehandles that should be taken in loading sequences.

Constraints (4), (5) and (6) ensure that every container is loaded with any order of loading sequence.

Table 1 illustrates the result of this formulation for the example shown in Fig.2, in which the $3^{\text {rd }}$ line shows the observed number of rehandles while the $4^{\text {th }}$ line shows the expected number of rehandles obtained from above formulation.

\subsubsection{Ship stability evaluation}

Ship stability is evaluated by three factors (see Derrett (1999) for details) in those the most important factor is GM which is the distance between the center of gravity $(\mathrm{G})$ and the metacenter (M), as shown in Fig. 3.

A small GM endangers the ship stability while the large one involves more rolling that can cause serious cargo damages. The reasonable GM is often said to be one meter, but this can change depending on the ship design and cargo condition.

GM is calculated by the following equation:

$$
G M=G_{0} M+\frac{\sum_{i} L_{i j} W_{i}}{S D+C B+\sum_{i} W_{i}}
$$

where

$L_{i j}$ : distance between the metacenter of ship and the container location $j$ onboard ship where container $i$ is loaded

$W_{i}$ : $\quad$ weight of container $i$

$S D: \quad$ ship's displacement without cargo

$C D$ : weight of containers already on board before loading sequence

$G_{0} M: \quad$ distance between the center of gravity of ship $\left(\mathrm{G}_{0}\right)$ and the metacenter $(\mathrm{M})$

To formulate the loading sequence, the GM contribution ratio is defined as $G M_{i j k}$ for the container at location $i$ on yard bay picked up and stored at cell position $j$ on ship bay by crane $k$. Therefore, the formulation with the maximization of GM can be defined as follows:

[PG]

Maximize $\sum_{i=1}^{N} \sum_{j=1}^{N} \sum_{k=1}^{M} G M_{i j k} x_{i j k}$

Subject to (1), (2), (4) -(8).

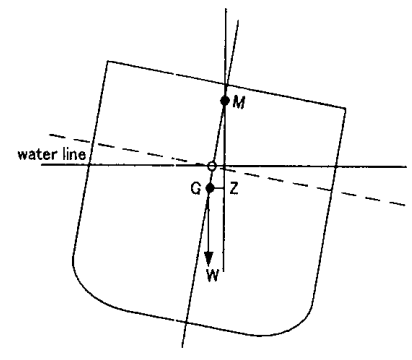

Fig.3 Ship gravity with metacenter \& gravity center

\subsubsection{SHCP Model}

Although the desirable GM is one meter in general, other values of GM are often used when taking into account other ship condition-related factors. Furthermore, loading planners and ship officers in charge of cargo handling may soften the GM restriction in order to reduce the number of required containers rehandles that prevent the quick ship turnaround. Such a trade-off analysis requires the non-inferior solutions to two objective problems.

Among a number of techniques for generating a non-inferior solution set, we employ the weighed sum of objective function method (Collette and Siarry, 2003). In this method, the problem is defined as a mathematical programming model with incorporated two objectives. Putting two objectives into a single objective with weights, the single objective problem is then defined as:

[PL]

Minimize

$w_{1} \sum_{i=1}^{N} \sum_{j=1}^{N} \sum_{k=1}^{M} R L_{i j k} x_{i j k}+w_{2} \sum_{i=1}^{N} \sum_{j=1}^{N} \sum_{k=1}^{M} G M_{i j k} x_{i j k}$

Subject to (1), (3) - (7),

$$
\begin{aligned}
& \sum_{i=1}^{N} \sum_{j=1}^{N} \sum_{k=1}^{M} G M_{i j k} x_{i j k} \geq g m \\
& \sum_{i=1}^{N} \sum_{j=1}^{N} \sum_{k=1}^{M} G M_{i j k} x_{i j k} \leq G m
\end{aligned}
$$

where $g m$ and $G m$ is the minimum and maximum GM guaranteed, respectively.

In objective (10), $w_{1}$ and $w_{2}$ are weights of the rehandles and GM objectives, in which $w_{2}$ is set negative because of the maximization of the $\mathrm{GM}$ while $w_{1}$ is positive because of minimization of number of rehandles.

$w_{1}-w_{2}=1$ 


\section{Heuristic Algorithms}

\subsection{Genetic Algorithms}

The solution procedure for SHCP may be categorized as a combinatorial optimization problem, including minimization of total rehandles and maximization of GM. This implies that there is no efficient exact algorithm for this problem. Consequently, the genetic algorithm, which is widely applied for plenty of practical mathematical programming, is employed as a heuristic for the nearly optimized solutions.

An example of the chromosome being use is shown in Fig. 4. In this chromosome, containers in yard bay 1 are handled by pair (QC-YC)1, hereafter referred as QC1 for short, while containers in yard bay 3 and 5 are handled by (QC-YC)2 or QC2.

As GA is commonly applied for a number of combinatorial optimization problems, we do not discuss about it in detail; however, its major characteristics follow:

(a) Fitness: A fitness value reflects the goodness of an individual, compared with the other individuals in the populations. In this study, since the $[\mathrm{PL}]$ is minimization problem, the smaller the objective function is, the higher fitness value must be. Considering some alternative fitness functions, the sigmoid function defined in (14) was found to be better where $y(x)$ denotes the objective function value:

$$
f(x)=1 /(1+\exp (y(x) / 10,000))
$$

(b) GA operators: Reproduction is a process where individual chromosomes are copies according to their scaled fitness function value. Two sophisticated selection schemes are tested to pick up a superior individual from the remainder: Roulette-wheel selection and Tournament selection. According to the preliminary computational tests, the former is chosen since giving better results. For

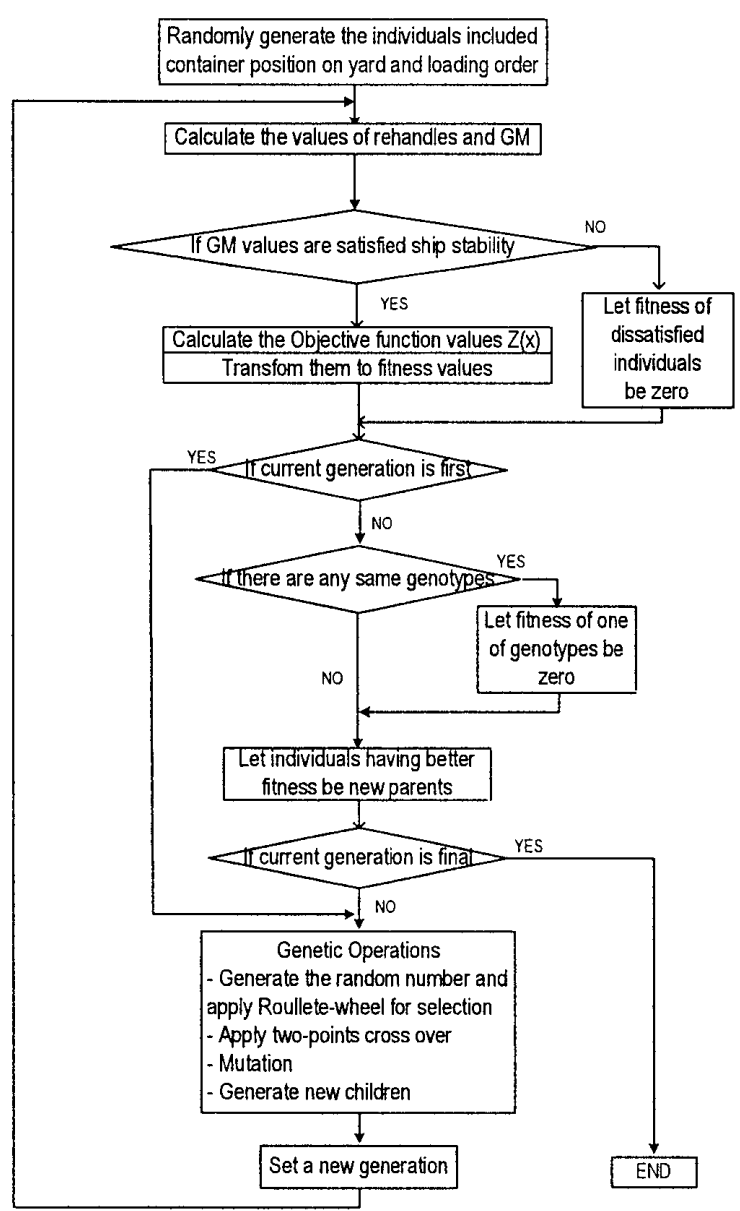

Fig.5 Genetic Algorithm Procedure

crossover procedure, after two types of crossover operator are tested by number of experiments, the so-called two-point crossover is employed. See Nishimura et al. (2001) for detail. Fig. 5 presents the application of GA's procedure.

\subsection{Ship holds partitioning and Crane assignment}

The main steps of algorithm are presented for ship holds partitioning and cranes assignment in order to analyze the ship stability and the terminal productivity.

Let $b_{k}$ is the number of yard bays associate with crane $k,(k=1, \ldots, M) . C_{k}$ is the number of containers

\begin{tabular}{|c|c|c|c|c|c|c|c|c|c|c|c|c|c|c|c|}
\hline Cell \# & 1 & 2 & 3 & 4 & 5 & 6 & 7 & 8 & 9 & 10 & 11 & 12 & 13 & 14 & 15 \\
\hline Order of loading sequence & 1 & 2 & 3 & 4 & 5 & 6 & & 1 & 2 & 3 & 4 & 5 & 6 & 7 & 8 \\
\hline Chromosome & 17 & 2 & 9 & 5 & 3 & 6 & 0 & 49 & 54 & 53 & 61 & 97 & 98 & 101 & 105 \\
\hline \multicolumn{16}{|l|}{ (Positions on yard) } \\
\hline Yard Bay \# & 1 & 1 & 1 & 1 & 1 & 1 & & 3 & 3 & 3 & 3 & 5 & 5 & 5 & 5 \\
\hline Crane \# & 1 & 1 & 1 & 1 & 1 & 1 & & 2 & 2 & 2 & 2 & 2 & 2 & 2 & 2 \\
\hline
\end{tabular}

Fig.4 Chromosome representation for 2 QCs assignment 
loaded by crane $k . Y B$ is the total number of yard bays. $S B$ is the number of available ship bays for loading sequence. The secure distance between two quay cranes is assumed to be the length of two bays.

Step 1: Let $k=1$

Step 2: Randomly initialize $N$ lowest positions in ship holds $p_{0}^{i}(i=1, \ldots, N)$, associate with types and destination of $N$ containers, with smallest number of ship bays.

Step 3: If $M=1$ stop. Otherwise let $k=2$ and go to step 4.

Step 4: If $k>M$, stop. Otherwise go to step 5 .

Step 5: If containers are separated into different blocks on yard, assign cranes to blocks. Otherwise go to step 6.

Step 6: Randomly select $b_{k}=\left(\overline{\left.P_{k}, Q_{k}\right)}\right.$, which $P_{k}$ and $Q_{k}$, respectively, are equal to $\left\{\left[\frac{Y B-\sum b_{k-1}}{M}-1\right]\right\}$ and $\left\{\left[\frac{Y B-\sum b_{k-1}}{M}+2\right]\right\}$

Step 7: From the ship's stern to her bow, if positions $p_{0}^{C_{k}}$ and $p_{0}^{C_{k+1}}$ are located on the same ship bay $\left(b_{u}\right)$, randomly choose $\left\{\left[\mathrm{O}_{1}\right]\right.$ or $\left.\left[\mathrm{O}_{2}\right]\right\}$ by checking if the number of ship bays is available.

Step 8: Assign quay crane $k$ to first available bay locations.

Step 9: Check the secure distance between two next quay cranes. If the distance can not be secured, move selected bays to the next ship bay.

Step 10: Let $k=k+1$ and go to step 4

Note:

Option 1 [01]: move all selected positions from $p_{0}^{c_{k+1}} \in b_{u}$ to ship bay $b_{u+1}$ in associated positions Option $2\left[\mathrm{O}_{2}\right]$ : move all selected positions from $p_{0}^{C_{k}} \in b_{u}$ back to top of ship bay $b_{u-1}$ in associated positions

\section{Numerical experiments}

The data to be used for the analysis are the container loading information observed in Port of Kobe. The input data include number of cranes, container volumes, types, weights and locations in yard stacks and in ship holds on board of three ships, each with a capacity of 800,1600 and 2400 TEUs. In this statistics, some containers on each ship were not to be handled at Kobe; therefore, these were not included in the analysis. The metacenter positions of the ships are not known and therefore; they are all assumed to be located at the upper deck level.

On the yard, containers are arranged in blocks, each block including the maximum of 20 bays and each bay containing the maximum of 6 rows and 4 containers high. Moreover, assuming that 20 foot container (referred as 20') and 40 foot one (40') can not be stored above empty positions in ship holds. Table 2 shows the container characteristics of all case studies, in which two container volumes are considered: 114 and 256 containers. Each volume has both $20^{\prime}$ and 40' containers.

For each ship, two models are considered: one for containers stored on deck and other for the ones in cargo holds. The weights $w_{1}$ and $w_{2}$ are estimated by the principle component analysis and their values seems reasonable because, as expected, both models have positive values of eigenvector for the rehandles and negative values for GM. Since the absolute values of the two eigenvectors are almost the same both for the "on-deck" and the "in-hold" model, planners intuitively take into account the rehandles and GM with the same weight in planning a loading sequence. The objective function coefficients $w_{1}$ and $w_{2}$ of the weighting method are presented in Table 3. Basically, the weights vary by the interval of 0.05 .

Table 2 Container characteristic of case studies

\begin{tabular}{|c|c|c|c|c|c|}
\hline \multirow{2}{*}{$\begin{array}{c}n \\
\text { (containers) }\end{array}$} & \multicolumn{2}{|c|}{ Size } & \multicolumn{3}{c|}{ Weights } \\
\cline { 2 - 6 } & $20^{\prime}$ & $40^{\prime}$ & Light & Medium & Heavy \\
\hline 114 & 80 & 34 & 26 & 64 & 24 \\
\hline 256 & 164 & 92 & 45 & 131 & 80 \\
\hline
\end{tabular}

Table 3 Set of weights

\begin{tabular}{|c|c|c|}
\hline Weight set & $w_{1}$ & $w_{2}$ \\
\hline 1 & 1.00 & -0.00 \\
\hline 2 & 0.95 & -0.05 \\
\hline 3 & 0.90 & -0.10 \\
\hline 4 & 0.85 & -0.15 \\
\hline$\cdot$ & & $\cdot$ \\
$\cdot$ & Interval $=0.05$ & $\cdot$ \\
\hline 18 & & $\cdot$ \\
\hline 19 & 0.15 & -0.85 \\
\hline 20 & 0.10 & -0.90 \\
\hline 21 & 0.05 & -0.95 \\
\hline & 0.00 & -1.00 \\
\hline
\end{tabular}


Table 4 Computational case studies

\begin{tabular}{|c|c|c|c|c|c|c|c|c|c|c|}
\hline \multirow{3}{*}{$\begin{array}{c}n \\
\text { Containers }\end{array}$} & \multirow{3}{*}{$\begin{array}{l}\text { Number of } \\
\text { (YCs-QCs) }\end{array}$} & \multirow{3}{*}{$\begin{array}{l}\text { Number of } \\
\text { Yard Bays }\end{array}$} & \multicolumn{3}{|c|}{ Number of Ship Bays } & \multirow{3}{*}{$\begin{array}{l}\text { Yard } \\
\text { Blocks }\end{array}$} & \multicolumn{4}{|c|}{ Crane Assignment } \\
\hline & & & \multirow{2}{*}{800 TEUs } & \multirow{2}{*}{1600 TEUs } & \multirow{2}{*}{2400 TEUs } & & \multirow{2}{*}{$\begin{array}{c}\text { YBs associate } \\
\text { with YCs }\end{array}$} & \multicolumn{3}{|c|}{ Ship bays associate with $\mathrm{QCs}$} \\
\hline & & & & & & & & 800 TEUs & 1600 TEUs & 2400 TEUs \\
\hline \multirow{3}{*}{114} & 1 & 7 & 5 & 4 & 3 & 1 & 7 & 5 & 4 & 3 \\
\hline & 2 & 7 & 5 & 4 & 3 & 1 & $\begin{array}{l}\{4-3\},\{2-5\} \\
\{3-4\},\{5-2\}\end{array}$ & $\{2-3\},\{3-2\}$ & $\{2-2\},\{1-3\},\{3-1\}$ & $\{2-1\},\{1-2\}$ \\
\hline & 3 & 7 & 5 & 4 & 3 & 1 & $\begin{array}{l}\{2-2-3\},\{2-3-2\} \\
\{1-3-3\},\{3-2-2\} \\
\{3-3-1\},\{3-1-3\}\end{array}$ & $\begin{array}{c}\{1-2-2\},\{2-1-2\} \\
\{2-2-1\}\end{array}$ & $\begin{array}{c}\{1-2-1\},\{1-1-2\} \\
\{2-1-1\}\end{array}$ & $\{1-1-1\}$ \\
\hline \multirow[b]{3}{*}{256} & 1 & 16 & 10 & 8 & 7 & 2 & 16 & 10 & 8 & 7 \\
\hline & 2 & 16 & 10 & 8 & 7 & 2 & $\{6-10\}$ & $\begin{array}{c}\{5-5\},\{4-6\},\{6-4 \\
\{3-7\},\{7-3\}\end{array}$ & $\{\{4-4\},\{3-5\},\{5-3\}$ & $\begin{array}{c}\{3-4\},\{4-3\},\{2-5\} \\
\{5-2\}\end{array}$ \\
\hline & 3 & 16 & 10 & 8 & 7 & 2 & $\begin{array}{c}\{6-5-5\},\{6-4-6\} \\
\{6-6-4\},\{6-3-7\} \\
\{6-7-3\}\end{array}$ & $\begin{array}{c}\{3-3-4\},\{3-4-3\} \\
\{2-4-5\},\{2-5-4\} \\
\{4-3-3\},\{4-2-4\} \\
\{4-4-2\},\{5-3-2\} \\
\{5-2-3\}\end{array}$ & $\begin{array}{l}4-2-2\},\{4-1-3\} \\
\{4-3-1\},\{3-2-3\} \\
\{3-3-2\},\{2-3-3\}\end{array}$ & $\begin{array}{c}\{4-2-1\},\{4-1-2\} \\
\{3-2-2\},\{2-3-2\} \\
\{2-2-3\}\end{array}$ \\
\hline
\end{tabular}
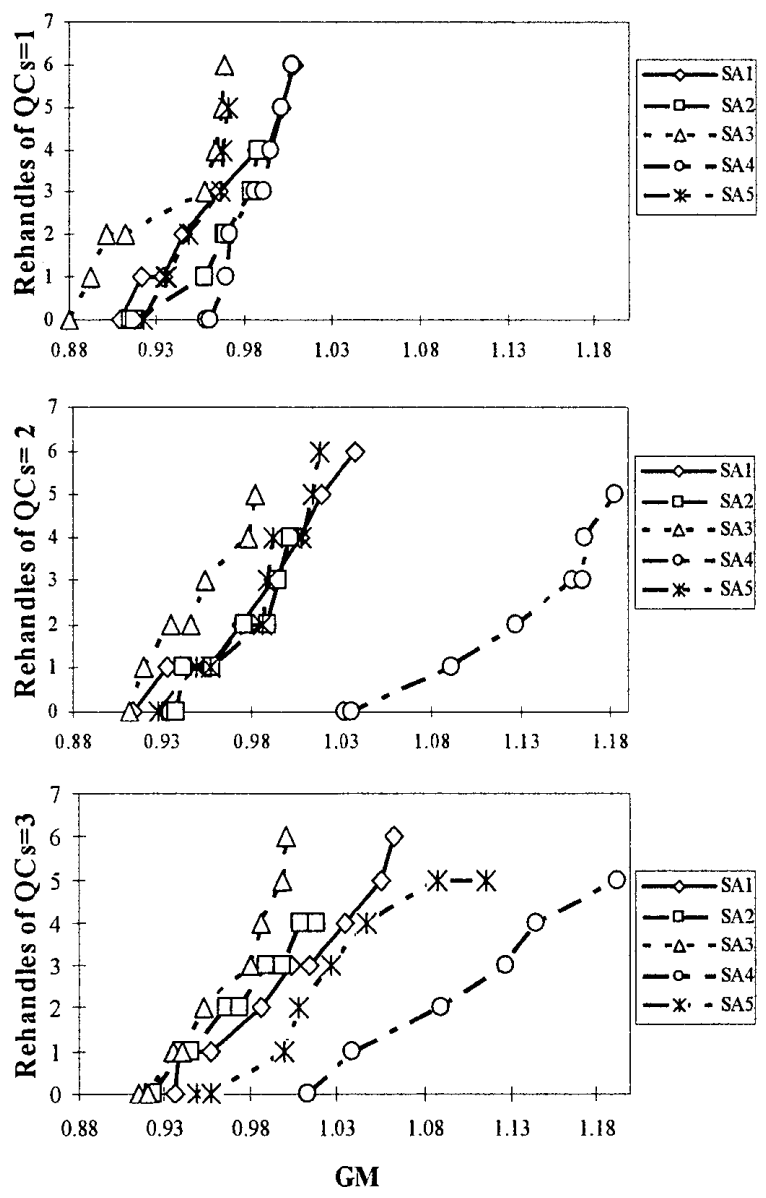

Fig. 6 Solutions set of loading 114 containers on the ship 800 TEUs with different number of QCs

An analysis is made with 20 sets of container stacks with the same stack density per each container volume (114, containers/168 slots and 256 container/384 slots), given by a uniform random distribution. 205 computational cases are set up as shown in Table 4, in which 87 cases are for 114 containers volume and 118 cases for 256 containers volume.
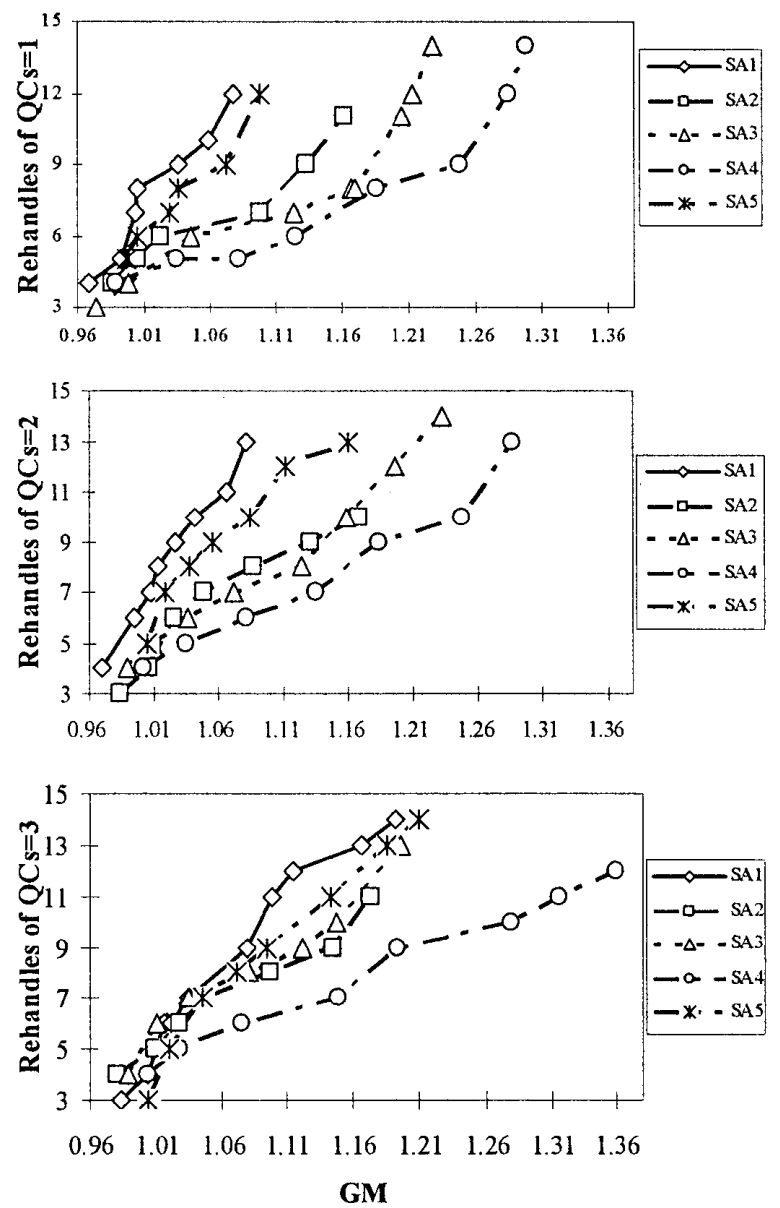

Fig.7 Solutions set of loading 256 containers on the ship 800 TEUs with different number of QCs

For each case, five stack arrangements (SA) are selected with uniform random number. The solution procedures were coded in " $\mathrm{C}++$ " language and all computer experiments have been performed on a $\mathrm{PC}$ Pentium IV. Three weight levels $(<=10 ;<=24 ;<=35$ tons) and three destinations are assumed. The maximum GM guaranteed of $1.42 \mathrm{~m}$ and the minimum one of $0.88 \mathrm{~m}$ are selected. By varying the weights $w_{I}$ and $w_{2}$, a non-inferior solution set is identified with 
the expected number of rehandles.

However, the goal of this paper is to identify the approximate non-inferior set not with the expected but with the rehandles that actually take place during the loading process. Therefore, the expected number of rehandles should be converted to the observed ones, which may causes some non-inferior solutions become inferior.

When the number of cranes varies from 1 to 3 , it does not cause much difference on the number of rehandles, in both cases of container volumes. The reason is the loading sequence is carried bay by bay and the positions in a ship holds are partitioned by types and destinations of containers. In contrast, the minimum GM is yielded for the case of one quay crane. The more QCs there are, the better GM is achieved.

Fig. 6 and Fig. 7 illustrate the results obtained with a different number of QCs while loading 114 and 256 containers to the ship 800 TEUs, respectively. In the 114 container volume case, the largest number of rehandles ranks from 5 to 6 depend on each specific $\mathrm{SA}$, while the GM is $1.008 \mathrm{~m}$ with $\mathrm{QCs}=1,1.183 \mathrm{~m}$ with $\mathrm{QCs}=2$ and $1.193 \mathrm{~m}$ with $\mathrm{QCs}=3$. Although the number of rehandles slightly changes upon each SA, it is quite obvious that the number of cranes does not make any alteration to total of unproductive work. The same trend exists for the 256 container volume case. As shown in Fig. 7, the maximum number of rehandles ranges from 13 to 14 in all of SAs with any number of cranes, whereas the maximum GM increases from $1.298 \mathrm{~m}$ to $1.396 \mathrm{~m}$ in the cases of $\mathrm{QCs}=1$ and $\mathrm{QCs}=3$, respectively. The results of other computational experiments carried with two other ships of 1600 and 2400 TEUs also have the similar inclination of GM and the number of rehandles.

Table 5 reports all solutions of rehandles ( $\mathrm{RH})$ obtained on each crane as well as comparison between the entire results for three ships with SA1. As recognized, the small ship case usually gives a larger number of rehandles than the large ship cases, whereas the large ship cases keep their stability balance better than the small ones. Typically, the loading plan for the ship of 800 TEUs causes many more rehandles than that of the 1600 TEU ship, and so does the 1600 TEU ship than the 2400 TEU ship, while the GM of the two latter ships do not change as much as the former one. Furthermore, the number of solutions increases together with number of cranes; so that, when using more cranes in handling sequence, the operator has more options to distribute the handling process depended on the facial situation.

With reference to the computational time, it is obviously that the CPU time shortly grows accordingly to number of cranes in all cases, but always less than one minute in all instances. However the different ship sizes do not have a visible effect on CPU time with the same container volume. The reason is the empty positions in ship holds are chosen by the ship partitioning heuristics developed in section 4, which selected the best positions in ship holds for loading task. This process does not extend the CPU time of main program when concerning to different ship size.

\section{Model improvement}

The selected loading plans have the least unproductively work and loading tasks with them are fast when the number of cranes is increased. In order for planner to more easily decide loading plans with faster resulting loading tasks, an additional formulation incorporated with loading time factors should be taken account as follows to select solutions among a non-inferior solution set.

It is assumed that the retrieving time of one container from any position on the yard by a transfer crane is predetermined.

$C_{k}$ : total number of containers loaded by crane $k$

$t_{1}$ : loading time for one container without any rehandle

$t_{2}:$ time for one rehandle

$R H_{k}$ : total rehandles completed by crane $k$

The time for total rehandles fulfilled by crane $k$ is:

$$
R \mathrm{H}_{k} t_{2}
$$

The time for the loading task without any rehandle completed by crane $k$ is:

$C_{k} t_{1}$

Total loading time of crane $k$ : $C_{k} t_{1}+R H_{k} t_{2}$

The solutions of loading 114 containers to the ship 800 TEUs, which now are considered with loading time factor, are illustrated in Table 6. Previously, solutions \#1 to \#7 are non-inferior according to GM and rehandles but when the time factor is considered, the solution \#2 and solution \#7 become less competitive than other ones. 
Table 5 Solutions of rehandles obtained of each crane with SA1

\begin{tabular}{|c|c|c|c|c|c|c|c|c|c|c|c|}
\hline \multirow{2}{*}{$\begin{array}{c}n \\
\text { Containers } \\
\end{array}$} & \multirow{2}{*}{ Solutions } & \multirow[t]{2}{*}{ Ship } & \multirow{2}{*}{$\begin{array}{l}\mathrm{RH} \text { of } \\
\mathrm{QCs}=1\end{array}$} & \multirow{2}{*}{$\begin{array}{l}\text { CPU time } \\
\text { (h.m.s) }\end{array}$} & \multicolumn{2}{|c|}{$\mathrm{RH}$ of $\mathrm{QCs}=2$} & CPU time & & of QC & & CPU time \\
\hline & & & & & $\mathrm{QCl}$ & $\mathrm{QC2}$ & (h.m.s) & $\mathrm{QC1}$ & $\mathrm{QC2}$ & $\mathrm{QC3}$ & (h.m.s) \\
\hline & 1 & & 0 & 00.04 .18 & 0 & 0 & 00.04 .21 & 0 & 0 & 0 & 00.04 .54 \\
\hline & 2 & & 1 & 00.04 .14 & 1 & 0 & 00.04 .33 & 0 & 1 & 0 & 00.04 .49 \\
\hline & 3 & & 2 & 00.04 .18 & 1 & 1 & 00.04 .38 & 1 & 1 & 0 & 00.04 .54 \\
\hline & 4 & 800 TEUs & 3 & 00.04 .16 & 2 & 1 & 00.04 .36 & 2 & 1 & 0 & 00.04 .56 \\
\hline & 5 & & 4 & 00.04 .14 & 3 & 1 & 00.04 .21 & 2 & 1 & 1 & 00.04 .51 \\
\hline & 6 & & 5 & 00.04 .15 & 3 & 2 & 00.04 .35 & 2 & 1 & 2 & 00.04 .56 \\
\hline & 7 & & 6 & 00.04 .16 & 4 & 2 & 00.04 .46 & 2 & 2 & 2 & 00.04 .54 \\
\hline & 1 & & 0 & 00.04 .12 & 0 & 0 & 00.04 .18 & 0 & 0 & 0 & 00.04 .42 \\
\hline & 2 & & 1 & 00.04 .14 & 1 & 0 & 00.04 .28 & 1 & 0 & 0 & 00.04 .43 \\
\hline & 3 & & 2 & 00.04 .11 & 1 & 1 & 00.04 .21 & 1 & 1 & 0 & 00.04 .50 \\
\hline & 4 & & 3 & 00.04 .12 & 2 & 1 & 00.04 .22 & 2 & 1 & 0 & 00.04 .49 \\
\hline & 5 & 1600 TEUs & 4 & 00.04 .10 & 2 & 2 & 00.04 .30 & 2 & 2 & 0 & 00.04 .52 \\
\hline & 6 & & - & - & - & - & - & 2 & 1 & 1 & 00.04 .49 \\
\hline 114 & 7 & & 5 & 00.04 .14 & 3 & 2 & 00.04 .26 & 2 & 2 & 1 & 00.04 .43 \\
\hline & 8 & & 6 & 00.04 .10 & 4 & 2 & 00.04 .18 & 3 & 2 & 1 & 00.04 .54 \\
\hline & 9 & & - & - & 3 & 3 & 00.04 .28 & 3 & 3 & 1 & 00.04 .49 \\
\hline & 10 & & 7 & 00.04 .14 & 4 & 3 & 00.04 .26 & 3 & 2 & 2 & 00.04 .50 \\
\hline & 1 & & 0 & 00.04 .10 & 0 & 0 & 00.04 .11 & 0 & 0 & 0 & 00.04 .31 \\
\hline & 2 & & 1 & 00.04 .11 & 1 & 0 & 00.04 .16 & 1 & 0 & 0 & 00.04 .36 \\
\hline & 3 & & 2 & 00.04 .08 & 1 & 1 & 00.04 .18 & 1 & 1 & 0 & 00.04 .32 \\
\hline & 4 & & 3 & 00.04 .04 & 2 & 1 & 00.04 .12 & 2 & 1 & 0 & 00.04 .31 \\
\hline & 5 & & 4 & 00.04 .12 & 2 & 2 & 00.04 .11 & 2 & 2 & 0 & 00.04 .38 \\
\hline & 6 & 2400 TEUs & 5 & 00.04 .08 & 3 & 2 & 00.04 .22 & 2 & 1 & 1 & 00.04 .38 \\
\hline & 7 & & - & - & - & - & - & 2 & 2 & 1 & 00.04 .31 \\
\hline & 8 & & 6 & 00.04 .09 & 4 & 2 & 00.04 .12 & 3 & 2 & 1 & 00.04 .32 \\
\hline & 9 & & - & - & 3 & 3 & 00.04 .11 & 2 & 2 & 2 & 00.04 .36 \\
\hline & 10 & & 7 & 00.04 .06 & 4 & 3 & 00.04 .09 & 3 & 3 & 1 & 00.04 .40 \\
\hline & 11 & &. & - & 5 & 2 & 00.04 .15 & 3 & 2 & 2 & 00.04 .35 \\
\hline & 1 & & 4 & 00.09 .45 & 2 & 2 & 00.10 .13 & 2 & 1 & 0 & 00.10 .39 \\
\hline & 2 & & 5 & 00.09 .48 & 4 & 2 & 00.10 .15 & 2 & 2 & 0 & 00.10 .42 \\
\hline & 3 & & - & - & 3 & 3 & 00.10 .08 & 2 & 1 & 1 & 00.10 .25 \\
\hline & 4 & & 7 & 00.09 .43 & 4 & 3 & 00.10 .15 & 3 & 2 & 1 & 00.10 .45 \\
\hline & 5 & & - & - & - & - & - & 3 & 3 & 1 & 00.10 .39 \\
\hline & 6 & & 8 & 00.09 .54 & 5 & 3 & 00.10 .13 & 3 & 2 & 2 & 00.10 .32 \\
\hline & 7 & & - & - & 4 & 4 & 00.10 .15 & 4 & 3 & 2 & 00.10 .42 \\
\hline & 8 & 800 TEUs & 9 & 00.09 .45 & 5 & 4 & 00.10 .13 & 4 & 2 & 3 & 00.10 .34 \\
\hline & 9 & & 10 & 00.09 .52 & 6 & 4 & 00.10 .18 & 5 & 4 & 2 & 00.10 .45 \\
\hline & 10 & & - & - & 5 & 5 & 00.10 .11 & 5 & 3 & 3 & 00.10 .42 \\
\hline & 11 & & - & - & 6 & 5 & 00.10 .15 & 5 & 4 & 3 & 00.10 .38 \\
\hline & 12 & & 12 & 00.09 .46 & - & - & - & 4 & 4 & 4 & 00.10 .34 \\
\hline & 13 & & - & - & 8 & 5 & 00.10 .19 & 5 & 4 & 4 & 00.10 .45 \\
\hline & 14 & & - & - & 7 & 6 & 00.10 .13 & 6 & 4 & 3 & 00.10 .39 \\
\hline & 15 & & - & - &. &. & - & 6 & 4 & 4 & 00.10 .38 \\
\hline & 1 & & - & - & 2 & 2 & 00.09 .58 & 2 & 1 & 1 & 00.10 .16 \\
\hline & 2 & & 5 & 00.09 .31 & 4 & 2 & 00.09 .52 & 2 & 2 & 1 & 00.10 .17 \\
\hline & 3 & & 6 & 00.09 .27 & 3 & 3 & 00.09 .52 & 3 & 2 & 2 & 00.10 .16 \\
\hline & 4 & & 7 & 00.09 .22 & 4 & 3 & 00.09 .53 & 3 & 3 & 2 & 00.10 .20 \\
\hline & 5 & & 8 & 00.09 .27 & 5 & 3 & 00.09 .52 & 4 & 2 & 2 & 00.10 .18 \\
\hline & 6 & & - & - & 4 & 4 & 00.09 .48 & 4 & 3 & 2 & 00.10 .17 \\
\hline 256 & 7 & & 9 & 00.09 .30 & 5 & 4 & 00.09 .59 & 5 & 2 & 2 & 00.10 .18 \\
\hline 256 & 8 & 1600 IEUS & 10 & 00.09 .29 & 6 & 4 & 00.09 .53 & 4 & 3 & 3 & 00.10 .16 \\
\hline & 9 & & 11 & 00.09 .22 & 7 & 4 & 00.09 .59 & 5 & 3 & 2 & 00.10 .22 \\
\hline & 10 & & - & - & 6 & 5 & 00.09 .47 & 5 & 4 & 3 & 00.10 .20 \\
\hline & 11 & & 12 & 00.09 .31 & 7 & 6 & 00.09 .52 & 6 & 3 & 3 & 00.10 .18 \\
\hline & 12 & & 13 & 00.09 .37 & 8 & 5 & 00.09 .56 & 6 & 4 & 2 & 00.10 .16 \\
\hline & 13 & & 14 & 00.09 .30 & 8 & 6 & 00.09 .53 & 6 & 4 & 3 & 00.10 .18 \\
\hline & 14 & & - & - & 7 & 7 & 00.09 .59 & 5 & 4 & 4 & 00.10 .20 \\
\hline & 1 & & - & - & - & - & - & 2 & 2 & 0 & 00.10 .05 \\
\hline & 2 & & 5 & 00.09 .31 & 3 & 2 & 00.09 .52 & - & - & - & - \\
\hline & 3 & & 6 & 00.09 .24 & 4 & 2 & 00.09 .41 & 3 & 2 & i & 00.10 .08 \\
\hline & 4 & & 7 & 00.09 .22 & - & - & - & - & . & - & - \\
\hline & 5 & & 8 & 00.09 .24 & 5 & 3 & 00.09 .52 & 4 & 2 & 2 & 00.10 .14 \\
\hline & 6 & & 9 & 00.09 .18 & 6 & 3 & 00.09 .51 & 4 & 3 & 2 & 00.10 .04 \\
\hline & 7 & & - & - & 5 & 4 & 00.09 .43 & 5 & 2 & 2 & 00.10 .11 \\
\hline & 8 & 2400 TEUs & 10 & 00.09 .11 & 6 & 4 & 00.09 .51 & 5 & 3 & 2 & 00.10 .14 \\
\hline & 9 & & - & - & - & - & - & 4 & 3 & 3 & 00.10 .08 \\
\hline & 10 & & 11 & 00.09 .18 & 6 & 5 & 00.09 .47 & 4 & 4 & 3 & 00.10 .06 \\
\hline & 11 & & - & - & - & - & - & 5 & 3 & 3 & 00.10 .14 \\
\hline & 12 & & 12 & 00.09 .11 & 7 & 5 & 00.09 .45 & 6 & 3 & 3 & 00.10 .03 \\
\hline & 13 & & 13 & 00.09 .22 & 7 & 6 & 00.09 .47 & 6 & 4 & 3 & 00.10 .12 \\
\hline & 14 & & 14 & 00.09 .24 & 8 & 6 & 00.09 .43 & 6 & 4 & 4 & 00.10 .14 \\
\hline & 15 & & - & - & 7 & 7 & 00.09 .41 & 7 & 4 & 3 & 00.10 .08 \\
\hline
\end{tabular}


Table 6 Improved solutions of loading 114 containers on the ship 800 TEUs with QCs $=2$

\begin{tabular}{|c|c|c|c|c|c|c|c|}
\hline \# & \multirow{G}{*}{$\begin{array}{c}\text { GM } \\
\text { Total }\end{array}$} & $\begin{array}{c}\text { RH of each } \\
\text { crane }\end{array}$ & \multicolumn{2}{|c|}{$\begin{array}{c}\text { Loading time of each } \\
\text { crane (h.m.s) }\end{array}$} & $\begin{array}{c}\text { Loading } \\
\text { time of } \\
\text { sequence } \\
\text { (h.m.s) }\end{array}$ \\
\cline { 4 - 8 } & & & QC1 & QC2 & QC1 & QC2 & \\
\hline 1 & 0.910 & 0 & 0 & 0 & 01.38 .56 & 01.53 .52 & 01.53 .52 \\
\hline 2 & 0.934 & 1 & 1 & 0 & 02.10 .20 & 01.31 .28 & 02.10 .20 \\
\hline 3 & 0.945 & 2 & 1 & 1 & 01.42 .16 & 01.57 .32 & 01.57 .32 \\
\hline 4 & 0.966 & 3 & 2 & 1 & 01.45 .36 & 01.57 .32 & 01.57 .32 \\
\hline 5 & 0.993 & 4 & 3 & 1 & 01.48 .56 & 01.57 .32 & 01.57 .32 \\
\hline 6 & 1.002 & 5 & 3 & 2 & 01.48 .56 & 02.00 .52 & 02.00 .52 \\
\hline 7 & 1.009 & 6 & 4 & 2 & 02.14 .40 & 01.38 .08 & 02.14 .08 \\
\hline
\end{tabular}

\section{Concluding remarks}

This paper addressed the effects of the number of handling cranes to the ship loading plan with a major concern on the ship stability and the total rehandles required. Given that the loading orders of a loading process within each loading sequence, the set of solutions should be determined in a way such that the total wasted work can be minimized, while keeping a reasonable stability for the ship. GA method generates approximately optimal solutions in a reasonably short time. A wide variety of experiments demonstrated that solutions by this method were acceptable for practice use.

\section{Acknowledgements}

The authors wish to thank Mr. Hidehiko Harada and Mr. Takahiro Sato (CY operators of Maersk Line Kobe Container Terminal) for the fruitful opinion supports

\section{References}

(1) Ambrosino, D., Sciomachen, A., Tanfani, E.: Stowing a container ship: the master bay plan problem. Transportation Research Part A 38, pp. 81-99, 2004

(2) Avriel, M., Penn, M., Shpirer, N., Witteboon, S.: Stowage planning for container ships to reduce the number of shifts. Annals of Operations Research 76, pp. 55-71, 1998

(3) Collette, Y., Siarry, P.: Multi-objective Optimization. Springer-Verlag Berlin Heidelberg New York, Berlin, 2003

(4) Derrett, D.R: Ship stability for Master and Mates. Butterworth-Heineman, Oxford, 1999

(5) Dubrovsky, O., Levitin, G., Penn, M.: A genetic algorithm with a compact solution encoding for the containership stowage problem. Journal of Heuristic 8, pp. 585-599, 2002

(6) Haghani, A., Kaisar, E.I.: A model for designing container loading plans for containerships. Annual Conference for Transportation Research Board, 2001

(7) Imai, A., Miki, T.: A heuristic algorithm with expected utility for an optimal sequence of loading containers into a containerized ship. Journal of Japan Institute of Navigation 80, pp. 117-124, 1989

(8) Imai, A., Nishimura, E., Papadimitriou, S., Sasaki, K.: The containership loading problem. International Journal of Maritime Economics 4, pp. 126-148, 2002

(9) Imai, A., Sasaki, K., Nishimura, E., Papadimitriou, S.: O.R. Applications: Multi-objective simultaneous stowage and load planning for a container ship with container rehandle in yard stacks. European Journal of Operational Research 171, pp. 373-389, 2006

(10) Nishimura, E., Imai, A., Papadimitriou, S.: Berth allocation planning in the public berth system by genetic algorithms. European Journal of Operation Research 131, pp. 282-292, 2001

(11) Sciomachen, A., Tanfani, E.: A 3D-BPP approach for optimizing stowage plans and terminal productivity. European Journal of Operation Research 183, pp. 1433-1446, 2006

(12) Wilson, I.D., Roach, P.A: Container stowage planning: a methodology for generating computerized solutions. Journal of the Operation Research Society 51, pp. 1248-1255, 2000

(13) Wilson, I. D., Roach, P., Ware, J.A: Container stowage pre-planning: Using search to generate solutions, a case study. Knowledge- Based System 14, pp.137-145, 2001

(14) Zhang, C.,Wan, Y., Liu, J., Linn, R.J: Dynamic crane deployment in container storage yards. Transportation Research Part B 36, pp. 537-555, 2002 


\section{Questions and answers}

Saburo Tsuruta (Tokyo University of Marine Science and Techonology)

Transportation should be considered in totally. So, is there any possibility that your results increase unloading time in other ports?

\section{Nguyen Thanh Thuy}

Thank you for your question.

This study is evaluated based on the normal loading sequence: containers are stowed in different ship holds separately by destinations. Thus, when unloading at a specific destination, all containers in a hold dedicated to that port are unloaded. Consequently, any unloading sequence plan does not cause any inconvenience in unloading containers at any port of call.

In contrast, other relevant studies work of optimal ship stowage plan which consider to a ship hold arrangement by random or by weight have to deal with the unloading plan in next port of ship routine, since the loading plan in consequent port will cause results in unloading time in next port. 